\title{
Sobre a pesquisa-ação na educação e as armadilhas do praticismo
}

\author{
Marilia Gouvea de Miranda \\ Universidade Federal de Goiás, Faculdade de Educação \\ Universidade Católica de Goiás, Departamento de Educação
}

\author{
Anita C. Azevedo Resende \\ Universidade Federal de Goiás, Faculdade de Educação \\ Universidade Católica de Goiás, Departamento de Psicologia
}

\section{Introdução}

O conceito de pesquisa-ação representa um veio privilegiado para a discussão de um dos maiores impasses enfrentados pelos educadores: a relação entre teoria e prática. A educação é, afinal, uma prática social constituída na estreita relação com o conjunto das ciências sociais e outras áreas do conhecimento. Descobrir-se no seio dessa contradição e seus desdobramentos e, ainda, apreender a tensão que lhe é inerente são condições de todos aqueles que pensam a educação e nela atuam, seja ela entendida em sua dimensão mais particular, que é a educação escolar, ou mais global, a cultura.

Mediante a pesquisa-ação - uma concepção de pesquisa que, desde o início, se define por incorporar a ação como sua dimensão constitutiva -, o pesquisador em educação não deixa dúvidas sobre a relevância conferida à prática em seu processo de investigação. Tratar-se-ia, assim, de uma pesquisa que articula a relação entre teoria e prática no processo mesmo de construção do conhecimento, ou seja, a dimensão da prática - que é constitutiva da educação - seria fonte e lugar privilegiado da pesquisa. Além disso, a própria investigação se converteria em ação, em intervenção social, possibilitando ao pesquisador uma atuação efetiva sobre a realidade estudada. Reflexão e prática, ação e pensamento, pólos antes contrapostos, agora seriam acolhidos em uma modalidade de pesquisa que considera a intervenção social na prática como seu princípio e seu fim último.

É precisamente na perspectiva da articulação entre teoria e prática que o presente artigo pretende abordar a noção de pesquisa-ação. Longe de pretender fazer uma exaustiva discussão sobre as características e possibilidades dessa importante modalidade de investigação, o que se propõe é pensar a pesquisa-ação e suas condições e possibilidades de articular a reflexão e a ação no contexto da prática educativa. Para tanto, terá que ser feita uma incursão na questão da produção do conhecimento no mundo moderno, passo necessário para a compreensão da articulação da relação entre teoria e prática nesse mesmo contexto. Em seguida, são feitas considerações sobre a modalidade de pesquisa-ação, a partir de autores aqui tomados como exemplos de 
distintas possibilidades de entendimento do termo, para, finalmente, sugerir os riscos inerentes ao suposto de resolução imediata da contradição entre teoria e prática: a instrumentalização da teoria e o praticismo na educação.

\section{Conhecimento e intervenção social}

O dilema das possibilidades e condições do conhecimento desde sempre tem sido um impasse para os homens, e tem-se restabelecido, por diferentes perspectivas, matizes teóricos e propostas metodológicas de variados aportes, em distintos momentos históricos. Afinal, quais são as condições de possibilidade de apreensão da realidade pelo sujeito de conhecimento? Qual é a relação desse conhecimento com a objetividade, com a prática? Seja na mitologia, na filosofia, nas ciências naturais, nas ciências humanas, nas artes, ou nas relações sociais cotidianas, a questão tem-se recriado e seu enfrentamento desafiado o pensamento e compreendido processos teóricos importantes. A discussão acerca da pesquisa-ação deve ser tomada como um desses momentos.

Nos quase três séculos que vão desde os finais de 1600 até meados de 1800, de Descartes a Comte, passando por Kant e Hegel, constituem-se as bases da moderna compreensão da relação entre o sujeito que conhece e a objetividade a ser conhecida, suas possibilidades e seus limites, suas condições e exigências - a constituição da razão como uma faculdade propriamente humana. Já em Descartes (1983, p. 29), a razão revelava-se substância e possibilidade da subjetividade de todos os homens, e não encontrava sua validade e garantia em Deus, mas no respeito a regras precisas: "o poder de bem julgar e distinguir o verdadeiro do falso, que é propriamente o que se denomina o bom senso ou a razão, é naturalmente igual em todos os homens".

Descortinavam-se o desencantamento, a secularização e a humanização da razão, que encontrará na ciência, particularmente na matemática, o fundamento do método a ser aplicado a todos os campos do saber, e mais: a afirmação do sujeito como portador de razão ante a um objeto que podia conhecer e sobre o qual existiria uma só verdade.

Essa fé na razão impregnaria o programa iluminista para o qual a extensão da razão a todos os campos do conhecimento, se era limitada pelo próprio fenômeno e não poderia ir além desse, não encontraria limites. Nenhum campo havia que não devesse ser submetido à indagação racional, inclusive a política e a religião. A conformação da ciência como o único conhecimento possível, e de seu método como o único válido, implicaria que o recurso a causas ou princípios que não fossem acessíveis a esse método não daria origem ao conhecer. E qualquer conhecimento que não recorresse a tal método também não teria valor. O método da ciência devia ser estendido a todos os campos da indagação e da atividade humana, e a vida humana deveria ser por ele guiada. Nessa perspectiva, o método da ciência constituiu-se descritivo, no sentido de que os fatos e as suas relações constantes foram compreendidos pelas leis que consentiam na sua previsão.

Assim, a possibilidade do conhecimento, o modo de conhecer, seu valor e finalidade deslocaram-se para a afirmatividade da forma, ou seja: a verdade havia de ser garantida mais pela forma como era obtida, pelos procedimentos e instrumentos, do que pelo conteúdo que pudesse revelar. A discussão epistemológica migrou para a afirmatividade de regras e métodos de bem conhecer, e a empiria constituiu-se como expressão exclusiva do real.

Já as ciências humanas e sociais, que se constituirão a partir de meados do século XIX, serão solidárias e contemporâneas de um questionamento radical dessa possibilidade de conhecimento, apreensão do objeto pelo sujeito que conhece e relação desse conhecimento com a objetividade e a prática históricas. Da complexa revolução social que a Europa transporia para o resto do mundo se desenvolveriam novas formas de sociabilidade, de entendimento, de objetivação que constituiriam novas realidades sociais e desafios para o conhecimento científico. Processaram-se a afirmação da razão, da ciência, da cultura secular e do comportamento, a indústria e a urbaniza- 
ção, a divisão do trabalho social e a mercantilização, num decurso crescente de intelectualismo e racionalidade que reduziu os espaços da tradição, da superstição, da religião.

A compreensão desse mundo complexo elaborou propostas distintas para o conhecimento da realidade. De um lado, foram traduzidos para o campo da sociedade, da cultura e do indivíduo os procedimentos que já haviam sido elaborados e continuavam a elaborar-se nas ciências físicas e naturais; de outro, produziram-se novos procedimentos de reflexão ante a originalidade dos acontecimentos e dilemas que caracterizavam a vida social e o indivíduo no mundo moderno. Institucionalizadas nesse quadro, as ciências humanas e sociais desenvolveram-se sobremaneira a partir da virada do século XX, enfrentando, sem resolver, as questões fundamentais da relação entre sujeito e objeto e entre teoria e prática.

O pensamento positivista foi um momento radical dessa elaboração. Assentou-se no suposto da ruptura entre o sujeito e o objeto, possibilitando a apropriação dos modelos e métodos das ciências naturais como garantia e critério da verdade do conhecer. A verdade do objeto estava assegurada pela fiel e comprovada apreensão empírica, pela possibilidade de repetição, refutação e experimentação, descrição do objeto em sua representação, forma de manifestação imediata ou aparência. Tanto mais verdadeiro seria o seu conhecimento quanto mais fossem fiéis sua descrição e representação, de maneira que qualquer sujeito poderia comprovar a sua verdade, desde que garantidos os mesmos procedimentos e regras de conhecer.

Não se distinguiram, nessa perspectiva, os momentos de pesquisa e de exposição do objeto. O processo do conhecer era a expressão exata do objeto conhecido. A descrição do caminho da pesquisa e de sua metodologia era já exposição do objeto investigado e confirmação de sua verdade. Este era o que a regra de conhecer permitia apreender, e essa regra era a garantia de seu conhecimento.

Afastando qualquer possibilidade de interferência do sujeito, portanto, as regras e os procedimentos interpuseram-se entre o sujeito e o objeto para garantir a inteireza presumida e interna deste, e a pesquisa não se comprometeu para além da representação desse mesmo objeto. E, como exigência de validade, confirmava-o, confirmando ao mesmo tempo uma realidade que podia ser explicada, quantificada, comprovada, prevista e, pois, controlada. Dessa forma, o conhecimento postulou-se objetivo e neutro. Contudo, ao descrever a realidade e afirmá-la na sua exterioridade, ele também se tornou confirmativo e, a despeito de sua pretensa neutralidade e isenção, acabou por constituir-se como prática, ao conceber como verdade a realidade manifesta, reiterando-a e confirmando-a.

A neutralidade ante a objetividade efetivou-se, portanto, como conservação e afirmação da realidade mesma, revelando-se pseudopretensão, porque efetivada historicamente como conservação, manutenção, funcionalidade e controle. Daí que se tenha realizado como prática tomada como aplicação e utilidade.

Entretanto, diante dos desafios que se colocavam no mundo que se revolucionava, já no século XIX, avançando para o século $\mathrm{XX}$, tendências e vertentes nas ciências humanas e sociais buscaram libertar-se da epistemologia das ciências naturais. Do modelo explicativo das abordagens positivistas, organicistas e funcionalistas, os cientistas sociais voltaram-se para uma abordagem compreensiva: "em lugar da 'causação funcional', a 'conexão de sentido', a 'compreensão', o mundo da vida, as ações e relações sociais, o indivíduo, a identidade, a alteridade, a subjetividade, os valores, os ideais, as fabulações" (Ianni, 2003, p. 21).

Tratava-se, nessa perspectiva, de assumir a unidade originária da relação entre sujeito e objeto, a investigação científica devendo aceitar o desafio de um objeto que não se revela pela descrição de sua manifestação, mas somente pela apreensão e compreensão da diversidade de seus nexos, processos e estruturas de diferentes ordens. Um objeto ao mesmo tempo singular e universal, particularidade e totalidade, que não se revela na sua expressão imediata e aparente, 
mas carrega o passado e o futuro na sua expressão presente, que é história, que faz história, que se transforma, que é razão, emoção, sentido, desejo. Enfim, um objeto que se põe como desafio, seja ele o indivíduo, a sociedade, o grupo, a classe, o movimento social, a escola, o ser humano na sua intricada e contraditória realidade individual e histórica: as formas das objetivações humanas que constituem a realidade objetiva e as subjetivações da objetividade que constituem o sujeito.

É nessa perspectiva que se compreende que "as ciências naturais realizam principalmente a explicação, ao passo que as ciências sociais propiciam principalmente a compreensão, reconhecendo-se que as artes surpreendem e fascinam pela revelação" (idem, p. 24-25, grifos do original). Assim, o desafio da compreensão da realidade social passou a ser enfrentado pelo sujeito que conhece num outro patamar.

Num sentido amplo, e de início, pode-se afirmar que o objeto constitui uma totalidade que conecta e sintetiza sentidos e significados, descortinando processos em desenvolvimento. A fidelidade ao objeto diz respeito à apreensão dos diferentes nexos que o constituem. No entanto, não se trata simplesmente de arrolar e descrever tais nexos, mas de apreendê-los como síntese significativa e histórica de seus processos, numa totalidade que não se reduz à relação de tudo que lhe diz respeito, mas se refere a um todo significativo que apreende o objeto como expressão objetivada de sujeitos humanos em condições históricas determinadas e elabora a síntese da experiência recriada pelo pensamento.

Tomadas dessa forma, a teoria e a prática constituem-se reciprocamente, porque a objetividade histórica e não-natural é, antes, produto de objetivações humanas. O objeto é sempre objetivação de sujeitos, e compreendê-lo é apreender os sentidos e significados humanos que ali se depositam. O seu conhecimento será o reconhecimento da história e, portanto, das práticas sociais que ali se cristalizaram, sendo o desvendamento da realidade ou o conhecimento produzido acerca dos seus objetos sempre práxis que descortina e se compromete com a realidade.
Esse debate fertilizou-se e ainda ecoa no presente, e pode ser retomado nos diferentes programas e projetos de pesquisa que, a partir da crítica às possibilidades postas na incorporação do modelo das ciências naturais aos objetos das ciências históricas, apresentam propostas de pesquisa e intervenção no campo social. E uma das perspectivas que podem ser apreendidas nessa direção é aquela que se convencionou chamar pesquisa-ação, que se constituiu a partir da primeira metade do século XX.

\section{Pesquisa-ação e prática social}

Diversos autores descrevem a trajetória da pesquisa-ação desde os anos de 1940 até o presente. Numa perspectiva bastante abrangente, é possível situá-la em dois grandes períodos: o primeiro, mais norte-americano, a partir da emergência do termo cunhado por Kurt Lewin nos anos anteriores à Segunda Guerra Mundial, indo até os anos de 1960; o segundo, mais europeu, australiano e canadense, do final dos anos de 1960 até os dias atuais (Barbier, 2002; André, 1995). Trata-se, na verdade, de um grande mosaico de concepções de pesquisa-ação, cuja abordagem qualitativa nas ciências sociais terá seu conceito, justificativa e explicitação metodológica constituídos a partir de distintas vinculações teóricometodológicas.

A noção de intervenção poderá variar de uma posição mais próxima à experimental (como a de Lessard-Herbert, 1991 apud Barbier, 2002) até projetos de ação social com vistas à solução de problemas coletivos (Thiollent, 1984). Assim, à pesquisa-ação são atribuídas leituras que adotam uma perspectiva mais explicativa (experimental) ou mais compreensiva (fenomenológica ou dialética). Em princípio, as abordagens da pesquisa-ação constituem-se como crítica ao positivismo, ainda que se possa entender que nem todas logrem afastar-se inteiramente dessa concepção. Também é certo que, em princípio, elas se situam como abordagens compreensivas, uma vez que reconhecem que "a realidade social não é algo que exista e possa ser conhecida com independência por 
aquele que queira conhecê-la, mas é uma realidade subjetiva, construída e sustentada por meio dos significados dos atos individuais" (Carr \& Kemmis, 1988, p. 116).

$\mathrm{Na}$ atualidade, delineiam-se algumas concepções que buscam distinguir-se dos aportes clássicos das ciências sociais descritos. Dentre outras, pode-se estabelecer um paralelo entre duas dessas novas releituras da pesquisa-ação: as abordagens francesa e canadense, destacando-se, respectivamente, René Barbier (2002) e André Morin (2004); e a abordagem australiana, cujos principais expoentes são Wilfred Carr e Stephen Kemmis (1988). Ao tomar como referência esses autores e algumas de suas obras, não se pretende uma exegese de seu pensamento e de sua produção, mas situar alguns aspectos gerais que permitem apreender os desdobramentos da pesquisa-ação no campo da educação na atualidade.

René Barbier (2002) atribui à pesquisa-ação o sentido de uma revolução epistemológica ainda não suficientemente explorada nas ciências humanas. Sua noção de pesquisa-ação é a de "uma arte de rigor clínico, desenvolvida coletivamente, com o objetivo de uma adaptação relativa de si ao mundo" (p. 67), o que implica uma mudança do sujeito (indivíduo ou grupo) com relação à sua realidade. Reputa como bastante próxima da sua noção a do canadense André Morin (2004), de quem agrega o sentido de pesquisaação "integral", que visa à mudança pela "transformação recíproca da ação e do discurso". Ambos recorrem à teoria da complexidade de Edgar Morin para contrapor-se ao "ideal de simplicidade" das ciências da natureza. Afinal, só um paradigma da complexidade poderia apreender o ser humano entendido como "uma totalidade dinâmica, biológica, psicológica, social, cultural, cósmica, indissociável" (Barbier, 2002, p. 87). Esse paradigma, como reconhece Barbier, impõe ao pesquisador uma visão sistêmica aberta: "Ele deve combinar a organização, a informação, a energia, a retroação, as fontes, os produtos e os fluxos, input e output, do sistema, sem fechar-se numa clausura para onde o leva geralmente seu espírito teórico" (idem, p. 91).
De uma perspectiva vinculada a Jürgen Habermas, os canadenses Carr e Kemmis (1988, p. 142-143), ao formularem sua concepção de pesquisa-ação na educação, defendem que a teoria educativa deve corresponder a cinco exigências: a) rejeitar as noções positivistas de racionalidade, de objetividade e de verdade; b) admitir a possibilidade de utilizar as categorias interpretativas dos docentes; c) encontrar meios para distinguir as interpretações que estão ideologicamente distorcidas das que não estão, devendo proporcionar também alguma orientação sobre como superar os auto-entendimentos distorcidos; d) preocuparse em identificar aspectos da ordem social existente que frustram a obtenção dos fins racionais, devendo poder oferecer explicações teóricas mediante as quais os docentes vejam como eliminar ou superar tais aspectos; e) reconhecer que a teoria educativa é prática no sentido de que a questão de sua consideração educacional seja determinada pela maneira pela qual se relaciona com a prática. Assim, a verdadeira finalidade da teoria educativa seria informar e guiar a prática dos educadores, indicando quais ações devem empreender se querem superar os problemas e eliminar as dificuldades.

Inegavelmente, podem ser feitas muitas distinções entre as abordagens de pesquisa-ação desses autores. No entanto, a que reputamos mais importante se refere aos aportes teóricos adotados: a teoria da complexidade de Edgar Morin (e o viés sistêmico que, ao seu modo, René Barbier e André Morin lhe conferem) e a teoria da ação comunicativa de Habermas, trazida por Carr e Kemmis.

Em que pesem as distinções entre as abordagens de Barbier e Morin, de um lado, e de Carr e Kemmis, de outro, são muitas as suas aproximações e elas são essenciais para a compreensão do que tem sido formulado como pesquisa-ação na atualidade, especialmente na educação. Primeiro, os autores são bastante incisivos na crítica ao positivismo nas ciências sociais, aos limites de sua noção cientificista de pesquisa, de objetividade, racionalidade e verdade. Segundo, com maior ou menor aproximação, recorrem às abordagens compreensivas para extrair delas as pos- 
sibilidades do sujeito (do conhecimento ou da ação) e dar significado à realidade vivida mediante categorias interpretativas. ${ }^{1}$ Terceiro, vinculam a noção da pesquisa à idéia de mudança, de transformação dos atores e sua realidade. Quarto, e conseqüentemente, investigam o conceito de pesquisa junto à ação, à prática, com a resolução dos saberes nas ciências humanas e sociais dando-se, preferencial ou exclusivamente, no campo da prática e da ação social. Quinto, postulam uma noção de totalidade que se afirma referida à prática e diz respeito a tudo que nela se constitui, abrangendo a ação e a experiência do sujeito. Sexto, a pesquisa-ação, mais do que uma abordagem metodológica, é um posicionamento diante de questões epistemológicas fundamentais, como a relação entre sujeito e objeto, teoria e prática, reforma e transformação social.

\section{O praticismo e seus riscos}

Quais as implicações desse posicionamento epistemológico para a pesquisa-ação? Antes de tudo, devese reconhecer o quanto é importante que a pesquisaação se posicione como crítica ao objetivismo estéril próprio do positivismo, e que possa buscar, na perspectiva compreensiva, uma apreensão da relação entre sujeito e objeto que contemple essas polaridades reciprocamente referidas e contraditórias. Está em causa, portanto, a natureza da relação entre sujeito e objeto nas ciências humanas e sociais. Adorno (1995) lembra que a separação entre sujeito e objeto, ao mesmo tempo real e aparente, se torna ideologia sempre que for fixada sem mediação. Por isso, deve-se evitar incorrer na armadilha de, ao se contrapor ao primado da objetividade, resvalar no subjetivismo. Mesmo porque "o sujeito tanto mais é quanto menos é, e tan-

1 Nesse ponto, há uma distinção importante a ser ressaltada em Carr e Kemmis com relação aos outros autores citados: os australianos afirmam que o limite da abordagem compreensiva (que eles chamam de interpretativa) seria o não-reconhecimento de que a realidade pode afetar ("deformar") a consciência. to menos quanto mais crê ser, quanto mais se ilude em ser algo para si objetivo" (p. 198).

É importante ressaltar a crítica que a pesquisaação faz a uma noção de teoria contemplativa e abstrata. A afirmação de Marx de que não se trata apenas de compreender o mundo, mas de buscar transformálo, é sempre presente e deve ser entendida na perspectiva das mediações constitutivas das relações postas entre sujeito e objeto, teoria e prática.

Deve-se, no entanto, estar atento para que o imperativo de transformação da realidade social não implique a perda da mediação teórica na apreensão dessa realidade. Nesse sentido, é importante discutir a tendência que hoje se verifica de estabelecer o primado da ação sobre a reflexão, da prática sobre a teoria, da experiência sobre o pensamento, tendência de que resultam pelo menos dois graves reducionismos: o praticismo e a instrumentalização da teoria (Miranda, 2004 , p. 21). O suposto de que a produção do conhecimento seja orientada para subsidiar a ação pode incorrer numa noção bastante pragmática de teoria, aquela que se orienta para um fim útil, o que viria a conferir-lhe um caráter de instrumentalidade ou, no limite, a sua negação como teoria. Não é demais lembrar que teoria e prática guardam entre si uma relação de contradição: mesmo sendo sempre e necessariamente vinculada à prática, teoria não é prática, não se reduz a esta e não pode orientar-se imediatamente pelo seu interesse.

Tal praticismo pode afetar a formação inicial e continuada do professor, especialmente tudo o que diga respeito ao seu trato com a teoria, entendida aqui de modo bastante abrangente e envolvendo, além das chamadas teorias da educação, a filosofia, as ciências humanas e sociais, a arte, a cultura humana. $\mathrm{O}$ ideal de formação não pode, por qualquer pretexto, passar ao largo da defesa de uma sólida formação teórica, cujo princípio não deveria ser a instrumentalidade da ação ("teoria para quê?"), mas a fecundidade da prática social em sua estreita vinculação com a mesma teoria. É nesse sentido que se deve propor a teoria efetivada como prática, sobretudo quando aquela exerce seu vigor crítico: crítica da sociedade, das refor- 
mas educacionais, das políticas públicas, dos conteúdos ensinados, das práticas de gestão, do discurso educacional, das teorias adotadas, da prática cotidiana. Não há dúvida de que o ponto de partida e de chegada dessa crítica seja a prática. Mas não há crítica possível sem a mediação da teoria. Como a teoria não é algo que possa ser buscado ou constituído para um fim dado (como instrumento), não há alternativa senão assegurar uma formação teórica aos professores. Isso, evidentemente, custa caro, requer uma mudança cultural de gigantescas proporções, contraria os interesses da indústria cultural e, sobretudo, tem o inconveniente de gerar um professorado crítico e reivindicativo, difícil de ser administrado.

Assim, uma grave consequiência do praticismo é que sua defesa vem alimentando a retórica reformista da educação e seus efeitos se vêm fazendo sentir nas diversas expressões de repúdio à teoria e à cultura acadêmica. Outra vez, são muitos os riscos: o aligeiramento da formação, a descaracterização da universidade como agência de formação de professores, a banalização da pesquisa, a redução das condições de autonomia e rigor para o exercício da crítica.

Voltando à questão da pesquisa-ação, deve-se considerar que, do ponto de vista da atuação pedagógica do professor, é preciso estar atento aos exageros do praticismo. Uma incorreta compreensão da pesquisa-ação pode gerar a falsa noção de que essa atuação deva orientar-se para a solução de problemas isolados na sala de aula ou escola. Ou seja, as idéias de ação, mudança, intervenção podem ficar condicionadas às exigências normativas e adaptativas da resolução de problemas imediatos: a boa pesquisa, a boa prática e a boa teoria seriam, assim, aquelas que presidiriam a efetiva solução dos problemas enfrentados individual ou coletivamente pelo professor. Não é preciso argumentar muito para demonstrar que efetivas soluções implicam muito mais que soluções pontuais e emergenciais, pois requerem mediações teóricas, históricas, políticas, sociais e culturais a serem construídas coletivamente, são reivindicativas e raramente se orientam pela adaptação dos indivíduos ou grupos ao já instituído.
Uma outra implicação de um incorreto entendimento da pesquisa-ação seria responsabilizar os sujeitos (da ação, da pesquisa) pela mudança pretendida, quando se sabe que - sob as mediações teóricas, históricas, políticas, sociais e culturais já referidas - são limitadas as possibilidades da ação individual docente. Pode-se incorrer no voluntarismo messiânico da ação bem-sucedida ou, o que é mais provável, no insucesso frustrante da ação malograda. Ambos os enredos contrariam uma atuação política refletida, realista e efetivamente transformadora.

Por fim, deve-se insistir no risco de fazer com que a pesquisa-ação seja convertida em estratégia de políticas públicas com a finalidade de imprimir reformas no campo da retórica e da ação do professor, quando então a sua discussão epistemológica e conceitual se transfere para normalizações instituidoras da prática docente. A instituição da pesquisa como prática comum e generalizada aos professores ou às escolas desconsidera que ela requer suporte institucional e acadêmico adequado, condições de trabalho compatíveis, além da disposição e do interesse dos docentes. Sem essas condições, pode-se alimentar uma retórica reformista que institui o imperativo de que o professor assuma sozinho a decisão e o risco de se contrapor a uma realidade que não dá sinais de pretender se transformar.

\section{Referências bibliográficas}

ADORNO, Theodor W. Sobre sujeito e objeto. In: Palavras e sinais: modelos críticos 2. ed. Tradução Maria Helena Ruschel. Petrópolis: Vozes, 1995. p. 62-75.

ANDRÉ, Marli. Etnografia da prática escolar. 5. ed. Campinas: Papirus, 1995.

BARBIER, René. A pesquisa-ação. Tradução Lucie Didio. Brasília: Plano, 2002.

CARR, Wilfred; KEMMIS, Stephen. Teoria crítica de la enseñanza. Barcelona: Martinez Roca, 1988.

DESCARTES, René. O discurso do método. In: Descartes. 3. ed. Tradução J. Guinsburg e Bento Prado Júnior. São Paulo: Abril Cultural, 1983. p. 35-79. 
IANNI, Octavio. Estilos de pensamento: explicar, compreender, revelar. Araraquara: Cultura Acadêmica; UNESP, 2003.

MORIN, André. Pesquisa-ação integral e sistêmica: uma antropopedagogia renovada. Tradução Michel Thiollent. Rio de Janeiro: DP\&A, 2004.

MIRANDA, Marília Gouvêa de. A pesquisa na prática profissional docente: limites e possibilidades. In: SILVA, Aurora H. F; EVANGELISTA, Ely G. S. (Orgs.). Caminhando e abrindo caminhos: trajetória da rede municipal de educação. Goiânia: Universidade Federal de Goiás, 2004. p. 15-27.

THIOLLENT, Michel. Notas para o debate sobre pesquisa-ação. In: BRANDÃO, Carlos (Org.). Repensando a pesquisa participante. São Paulo: Brasiliense, 1984. p. 82-103.

MARILIA GOUVEA DE MIRANDA, doutora em educação pela Pontifícia Universidade de São Paulo (PUC/SP), é professora da Faculdade de Educação da Universidade Federal de Goiás e do Departamento de Educação da Universidade Católica de Goiás. Últimas publicações: Sobre tempos e espaços da escola: do princípio do conhecimento ao princípio da socialidade (Educação \& Sociedade, Campinas: CEDES, v. 27, n. 91, p. 639-651, 2005); A psicologia da educação na perspectiva da relação teoria e prática: uma conciliação possível? (In: REUNIÃO ANUAL DA ANPEd, 28., 2005, Caxambu. Anais... 1 CD-ROM); O professor pesquisador e sua pretensão de resolver a relação teoria e prática na formação de professores (In: ANDRÉ, Marli (Org.). O papel da pesquisa na formação e na prática dos professores. 4. ed. Campinas: Papirus, 2005, p. 129-143).E-mail: mgmiranda@uol.com.br

ANITA C. AZEVEDO RESENDE, doutora em ciências sociais pela PUC/SP, é professora da Faculdade de Educação da Universidade Federal de Goiás e do Departamento de Psicologia da Universidade Católica de Goiás, e pesquisadora do CNPq. Últimas publicações: Subjetividade: novas abordagens de antigas antinomias (In: REUNIÃO ANUAL DA ANPEd, 28., 2005, Caxambu. Anais... 1 CD-ROM); Subjetividade e educação: um não-tão-novo desafio para um não-tão-novo mundo (Educ Ativa, Goiânia, v. 6, n. 2, p. 311-321, jan./dez. 2003); O processo de individualização: alienação (Estudos, Goiânia, v. 30, n. 1, p. 201215, 2003).E-mail: anita.resende@ pesquisador.cnpq.br

Recebido em fevereiro de 2006 Aprovado em julho de 2006 
Marilia Gouvea de Miranda e Anita C. Azevedo Resende

Sobre a pesquisa-ação na educação e as armadilhas do praticismo

A pesquisa-ação, uma modalidade de pesquisa muito utilizada na educação, é 
abordada na perspectiva de suas contribuições e de seu duplo risco: o praticismo e a instrumentalização da teoria. $\mathrm{O}$ artigo parte de ampla discussão sobre as condições e possibilidades do conhecimento nas ciências sociais no mundo moderno, para situar a pesquisaação como uma proposta de pesquisa e intervenção na realidade social. Após uma exposição da trajetória da pesquisa-ação, distingue duas grandes tendências de releitura dessa modalidade de pesquisa nos dias atuais: as abordagens francesa e canadense, destacando-se, respectivamente, René Barbier e André Morin; e a abordagem australiana, cujos principais expoentes são Wilfred Carr e Stephen Kemmis.

Palavras-chave: pesquisa-ação; pesquisa educacional; teoria e prática

On action research in education and the snares of practicism

Action research, a type of research frequently employed in education, is approached from the perspective of its contributions and its double risk: practicism and instrumentalization of theory. Starting with a broad discussion on the conditions and possibilities of knowledge in social sciences in the modern world, action research is conceived as a proposal for research and intervention in the social reality. After discussing the trajectory of action research, the article distinguishes two strong tendencies in this modality of research: the French and Canadian approaches, emphasizing René Barbier and André Morin respectively; and the Australian approach, whose main exponents are Wilfred Carr and Stephen Kemmis.

Key words: action research; educational research; theory and practice

\section{Sobre la pesquisa-acción en la educación y las trampas de la practicidad}

La pesquisa-acción, un modo de encuesta muy utilizada en la educación, es abordada en la perspectiva de sus contribuciones y de su doble riesgo: la practicidad y la instrumentación de la teoría. El artículo parte de una amplia discusión sobre las condiciones y posibilidades del conocimiento en las ciencias sociales en el mundo moderno, para situar la pesquisa-acción como una propuesta de pesquisa e intervención en la realidad social. Después de una exposición de la trayectoria de la pesquisa-acción, distingue dos grandes tendencias de relectura de esa modalidad de pesquisa en los días actuales: los abordajes francés y canadiense, destacándose, respectivamente, René Barbier y André Morin; y el abordaje australiano, cuyos principales exponentes son Wilfred Carr y Stephen Kemmis.

Palabras claves: pesquisa-acción; pesquisa educacional; teoría y práctica 